\title{
Critical Congenital Heart Disease Detection in the Screening Era: Do Not Neglect the Examination!
}

\author{
Deepika Sankaran, MD ${ }^{1}$ Heather Siefkes, MD, MSCl${ }^{2}$ Frank F. Ing, MD, FACC, MSCAI ${ }^{3}$ \\ Satyan Lakshminrusimha, MD ${ }^{1}$ Francis R. Poulain, MD ${ }^{1}$
}

${ }^{1}$ Division of Neonatology, Department of Pediatrics, University of California, Davis, Sacramento, California

${ }^{2}$ Division of Pediatric Critical Care Medicine, Department of Pediatrics, University of California, Davis, Sacramento, California

${ }^{3}$ Division of Pediatric Cardiology, Department of Pediatrics, University of California, Davis, Sacramento, California

Address for correspondence Deepika Sankaran, MD, Division of Neonatology, Department of Pediatrics, University of California, Davis Medical Center, 2516 Stockton Boulevard, Sacramento, CA 95817 (e-mail: dsankaran@ucdavis.edu; deepikasnkrn@gmail.com).

AJP Rep 2021;11:e84-e90.
Abstract
Keywords
- newborn
- congenital heart disease
- pulse oximetry
- CCHD screening
- pulmonary atresia
- PA-VSD
- oximetry screening
- false negative
- pulse oximetry screening
- critical congenital heart disease

Pulse oximetry oxygen saturation $\left(\mathrm{SpO}_{2}\right)$-based critical congenital heart disease $(\mathrm{CCHD})$ screening is effective in detection of cyanotic heart lesions. We report a fullterm male infant with normal perfusion who had passed the CCHD screening at approximately 24 hours after birth with preductal $\mathrm{SpO}_{2}$ of $99 \%$ and postductal $\mathrm{SpO}_{2}$ of $97 \%$. Detection of a loud systolic cardiac murmur before discharge led to the diagnosis of pulmonary atresia (PA) with ventricular septal defect (PA-VSD) by echocardiogram. The infant was transferred to a tertiary care center after initiation of prostaglandin $E 1$ (PGE1) therapy. Throughout the initial course, he was breathing comfortably without respiratory distress or desaturations on pulse oximetry. We believe that this is the first documented report of PA missed by CCHD screening. Thorough and serial clinical examinations of the newborn infant proved vital in the timely diagnosis of this critical disease. We review the hemodynamics and the recent literature evaluating utility of CCHD screening in the diagnosis of PA-VSD. Pulse oximetry-based CCHD screening should be considered a tool to enhance CCHD detection with an emphasis on detailed serial physical examinations in newborn infants.
Congenital heart diseases (CHDs) are the most common congenital malformations with an incidence of 5 to 10 per 1,000 live births, and a quarter of them qualify as critical CHDs (CCHD). ${ }^{1,2}$ Prior to universal oxygen saturation $\left(\mathrm{SpO}_{2}\right)$ based CCHD screening, up to $10 \%$ of all infant deaths were attributed to CHDs. ${ }^{3,4}$ Although a substantial number of infants with CCHDs could be detected by screening, an equal number of infants with CCHD may be missed. Acyanotic lesions, such as coarctation of the aorta, are commonly missed and present clinically within the first 2 weeks with rapid deterioration after the ductus arteriosus (PDA) closes. On the other hand, there are no published reports of pulmonary atresia (PA) that were missed by oximetry screening. 5 received

December 4, 2020 accepted after revision February 5, 2021
DOI https://doi.org/ $10.1055 / \mathrm{s}-0041-1727275$ ISSN 2157-6998.

\footnotetext{
(C) 2021. The Author(s).

This is an open access article published by Thieme under the terms of the Creative Commons Attribution-NonDerivative-NonCommercial-License, permitting copying and reproduction so long as the original work is given appropriate credit. Contents may not be used for commercial purposes, or adapted, remixed, transformed or built upon. (https://creativecommons.org/ licenses/by-nc-nd/4.0/) Thieme Medical Publishers, Inc., 333 Seventh Avenue, 18th Floor, New York, NY 10001, USA
} 


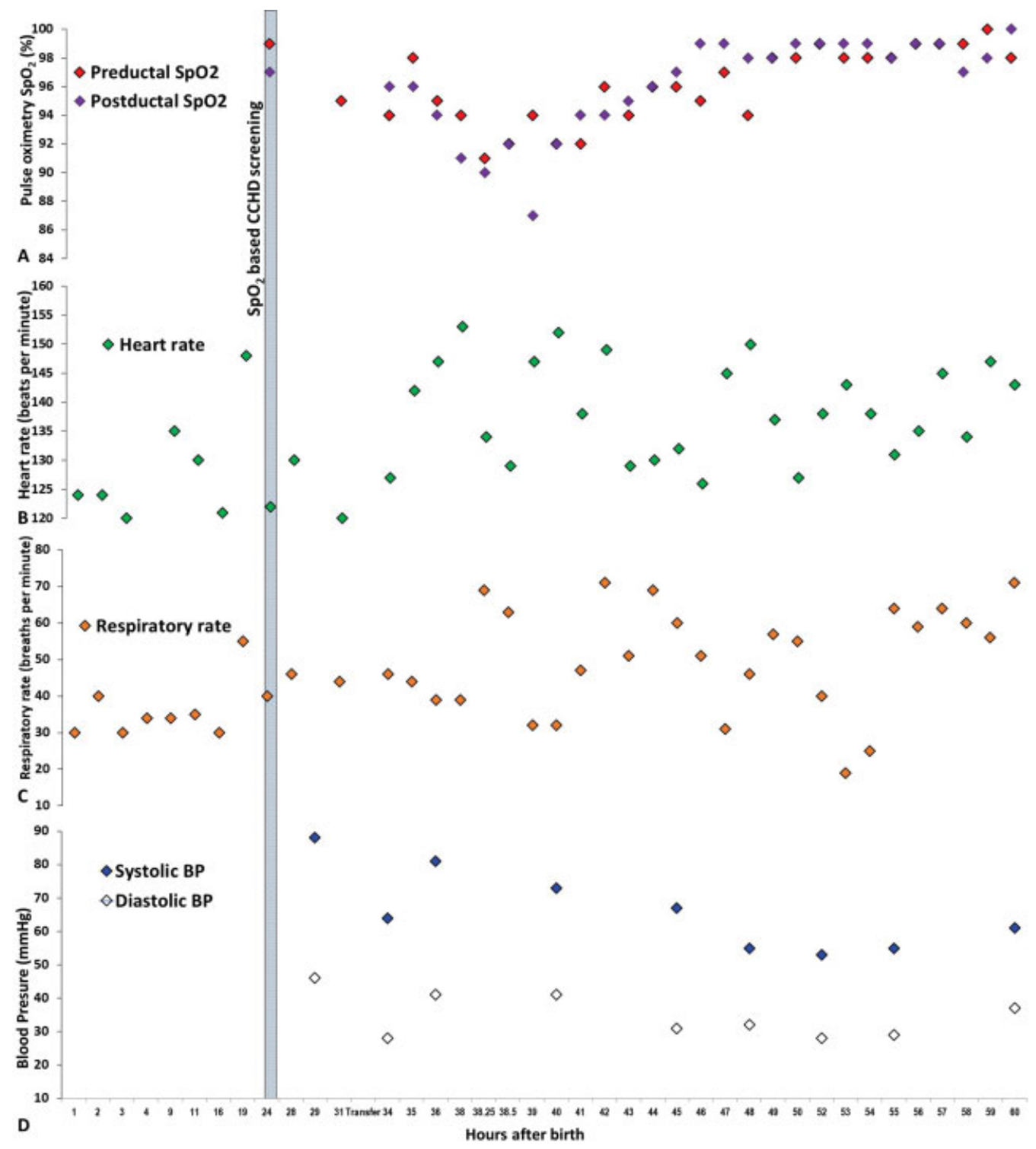

Fig. 1 Changes in the pulse oximetry saturation (A), heart rate (B), respiratory rate (C), and blood pressures (D) in the infant from birth until 60 hours after birth. The shaded area depicts the timing of $\mathrm{SpO}_{2}$ based CCHD screening. BP, blood pressure; CCHD, critical congenital heart disease; $\mathrm{SpO}_{2}$, pulse oximetry oxygen saturation.

\section{Patient Presentation}

A term male infant was delivered in a community hospital by cesarean section due to category-II fetal heart tracing. The antenatal history was unremarkable except for gestational hypertension. The mother had normal fetal anatomy ultrasound at 20 weeks of gestation. The baby had routine care in the delivery room with Apgar scores of 7 and 9. He had normal physical examination except for left-sided undescended testis. The baby was breastfeeding well, had normal vital signs, and the subsequent physical examinations on the day of birth did not demonstrate any cardiac murmur.

Twenty-four hours after birth, the infant passed $\mathrm{SpO}_{2}$ based CCHD screening with preductal and postductal $\mathrm{SpO}_{2}$ of 99 and 97\%, respectively. At 27 hours after birth, he was noted to have a grade 3 of 6 systolic murmur heard all over the precordium best heard in the left second intercostal space, with normal first and single second heart sounds.
Detailed examination showed normal cardiac apical impulse on the left side, normal peripheral pulses, no bruit, clear breath sounds bilaterally, and no hepatomegaly. His respiratory rates and heart rates were normal at this time (-Fig. 1). Echocardiogram was performed due to the murmur and revealed PA with a ventricular septal defect (PAVSD, - Fig. 2). The aorta was overriding the VSD and the flow across the patent ductus arteriosus (PDA diameter of $0.4 \mathrm{~cm}$ ) was left to right. The infant was started on intravenous prostaglandin E1 (PGE1) therapy at $0.025 \mu \mathrm{g} / \mathrm{kg} / \mathrm{min}$ and was transferred to a level-IV neonatal intensive care unit. During and after the transfer, he continued to have $\mathrm{SpO}_{2}$ greater than $95 \%$ while breathing comfortably in room air (-Fig. 1) when the $\mathrm{SpO}_{2}$ was measured using three different pulse oximeters at the community hospital (MasimoSET 2329 sensor with a GE B450 monitor), during the transfer (Masimo 4003 sensor with a Phillips Intellivue MP 70 monitor) and at the tertiary hospital (Masimo 4003 sensor with a 


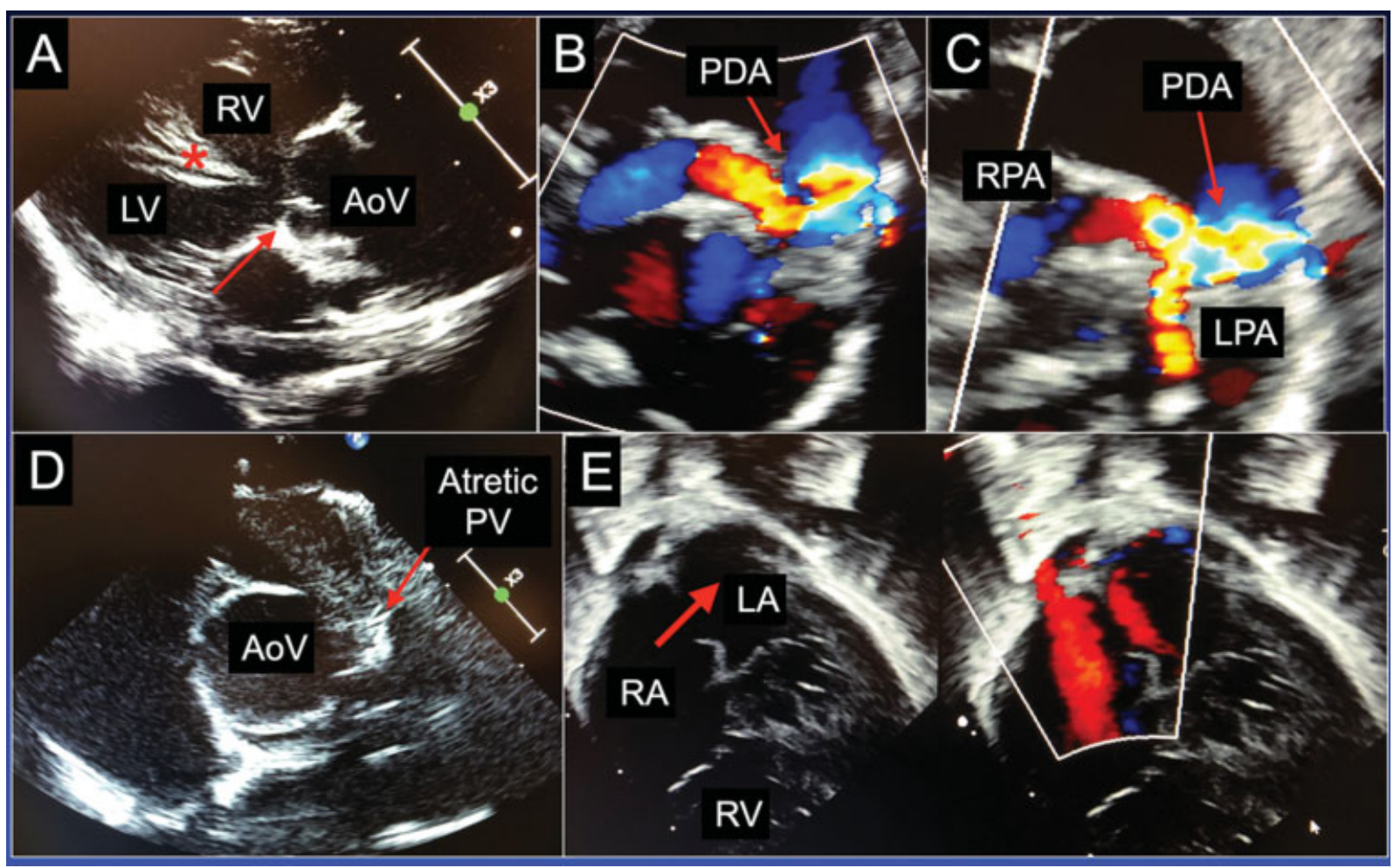

Fig. 2 Images from echocardiogram on admission to tertiary hospital. (A) Aorta valve (AoV; red arrow) overriding the interventricular septum (red asterisk): the overriding aortic valve position allows blood from both the right ventricle (RV) and the left ventricle (LV) to flow into the aorta thus creating complete mixing of oxygenated and deoxygenated blood. (B) Color flow Doppler showing a tortuous patent ductus arteriosus (PDA) (red arrow) originating off the underside of the distal aortic arch. (C) Color flow Doppler showing PDA flow (red arrow) to both the right pulmonary artery (RPA) and left pulmonary artery (LPA). (D) Short axis view showing the atretic pulmonary valve (red arrow) adjacent to the aortic valve seen en-face. (E) Four-chamber view (2D and color flow) showing an atrial septal defect. Note the septum bows right to left due to higher pressures in the right atrium (RA) with potential shunting of blood from the RA to the left atrium (LA; red arrow). 2D, two-dimensional.

Zoll X Series monitor). The baby had normal capillary refill, peripheral pulses, and blood pressures. At 38 hours after birth, the infant had respiratory distress that briefly required nasal continuous positive airway pressure of $5 \mathrm{~cm} \mathrm{H}_{2} \mathrm{O}$ with $21 \%$ inspired oxygen that was quickly weaned off within the next few hours to room air. His chest radiograph showed normal lung fields with mild prominence of pulmonary vascularity (-Fig. 3). On the day 2 after birth, the baby underwent cardiac catheterization with the intent to stent the ductus. Unfortunately, the PDA was too large for a stent and hence a Blalock-Taussig (BT) shunt was placed to secure pulmonary flow. The 12-lead electrocardiogram (EKG) at 5 days after birth showed upright T-waves on lead V1 (-Fig. 4) suggestive of right ventricular hypertrophy (RVH) with a strain pattern.

His clinical course was complicated by difficulty in tolerating feeds. He was found to have malrotation for which he underwent Ladd's procedure with gastrostomy tube placement at 4 weeks and an H-type tracheoesophageal fistula that was surgically ligated at 5 weeks of age. On genetic evaluation, his microarray was normal and his spine radiograph was normal. The renal ultrasound showed grade one hydronephrosis. The infant was suspected to have VACTERL (vertebral anomalies, anal atresia, cardiac defects, tracheoesophageal fistula, renal anomalies and limb anomalies) association. He was discharged home at 8 weeks of age.

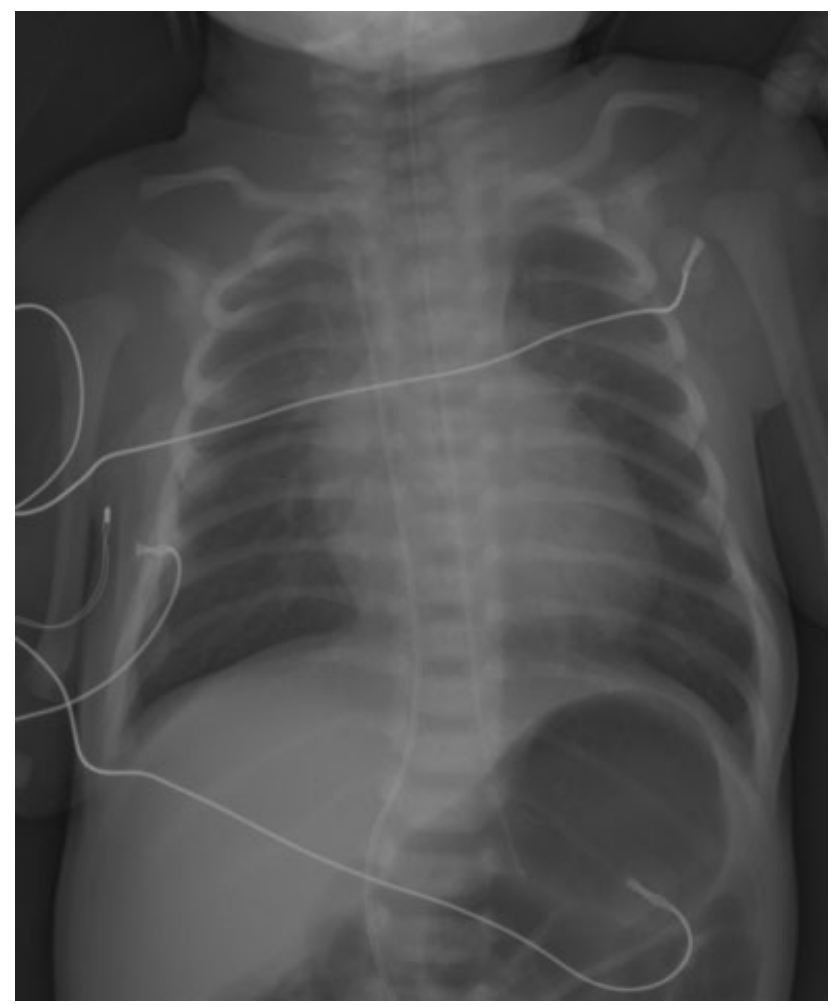

Fig. 3 Chest and abdomen radiograph of the infant at 2 days after birth notable for absence of pulmonary congestion or cardiomegaly. 


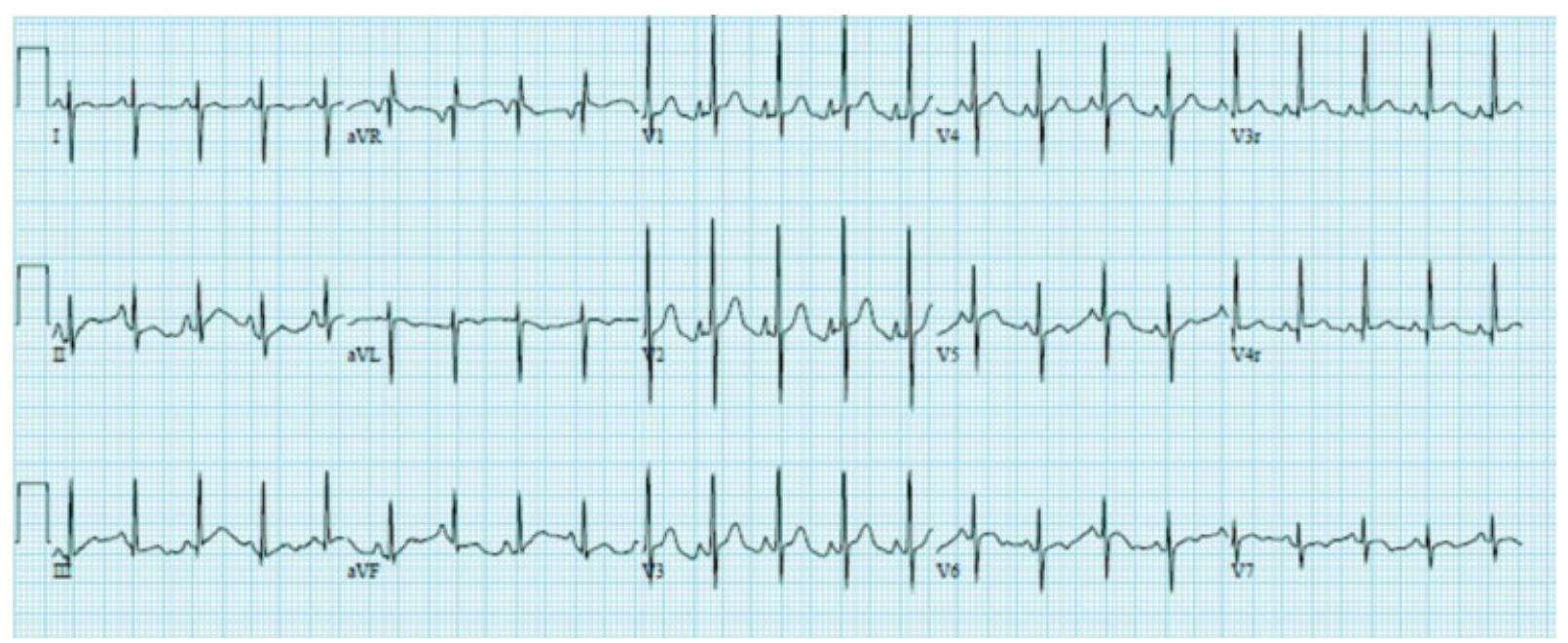

Fig. 4 Electrocardiogram at 5 days after birth notable for an upright T-wave on lead V1 which would be abnormal beyond 48 hours in a newborn and would indicate right ventricular strain.

During his outpatient cardiology follow-up, an aberrant right subclavian artery and partial anomalous pulmonary venous return (PAPVR) of the right-sided pulmonary veins were detected, and a complete repair of PAPVR along with that of PA-VSD was performed at 5 months of age.

\section{Discussion}

The term PA-VSD has been used to describe a group of CHDs with the common features of absence of intraluminal continuity between the pulmonary artery and the right ventricle, and the presence of a nonrestrictive interventricular septal defect. The pulmonary valve is atretic and the pulmonary trunk may also be hypoplastic. ${ }^{6}$ The perimembranous VSD (in PA-VSD) is often associated with an overriding aorta and described as "tetralogy type VSD," a type of anterior malalignment defect. ${ }^{7}$ This condition could be associated with DiGeorge's syndrome, VACTERL association, and occasionally with tracheomalacia or bronchomalacia. ${ }^{7}$ In PA-VSD, the source of pulmonary blood flow (Qp) is from the systemic circulation and is dependent on either major aortopulmonary collateral arteries (MAPCAs) in two-thirds of the cases or on the PDA. MAPCAs represent segmental branches of the descending aorta or indirect branches arising from the aortic arch vessels. When MAPCAs are absent, PGE1 therapy is initiated to maintain patency of the ductus arteriosus followed by placement of a ductal stent or a BT shunt to ensure adequate $\mathrm{Qp}$ for oxygenation of blood. Complete repair is performed at a later time.

The absence of direct ventricular connection to the pulmonary arterial system in PA-VSD results in complete mixing of the systemic and pulmonary venous blood with identical oxygen saturations in both the pulmonary arteries and the aorta. In a complete mixing lesion, the systemic oxygen saturation is dependent on the ratio of Qp and systemic (Qs) blood flows. Depending on the mixed venous saturation (50-70\%), a Qp:Qs ratio of 1 to 2:1 results in systemic oxygen saturation of 75 to $85 \%$, since the pulmonary venous oxygen saturation is usually $100 \%{ }^{8}$ At lower Qp:Qs ratios, a small increase in the ratio results in a large increase in $\mathrm{SpO}_{2}$, whereas at higher Qp:Qs ratios, a similar increase in the ratio would result in a smaller increase in $\mathrm{SpO}_{2}$. The infant discussed here had saturations that were consistently greater than 95\%, which would entail Qp:Qs ratio of at least 4-6:1 (theoretically, one aliquot of mixed venous saturation of $70 \%$ and four aliquots of pulmonary venous saturation of $100 \%$, $\mathrm{Qp}: \mathrm{Qs}$ of $4: 1$ would results in $\mathrm{SpO}_{2}=[70+100+100+100$ $+100] / 5=94 \%$ ). Such high Qp:Qs ratios would be expected to lead to pulmonary congestion presenting with respiratory distress and prominent pulmonary vascularity on chest radiograph. Our patient did not have evidence of respiratory or hemodynamic stress. We speculate that newborn infants can tolerate much higher pulmonary blood flow for several hours prior to becoming symptomatic. This may be due to higher pulmonary vascular resistance in the early postnatal period that dramatically falls at births and continues to fall over the next few days. We consider the theoretical possibility of preferential streaming of oxygenated blood to systemic circulation and deoxygenated blood to pulmonary circulation. The later detection of PAPVR may partially explain the presence of higher $\mathrm{SpO}_{2}$ in our patient due to higher mixed venous oxygen saturation without requiring a higher Qp.

Beginning in 2011, universal screening for CCHDs using pulse oximetry was adopted across the Unites States. ${ }^{2,9,10}$ It is estimated that the introduction of pulse oximetry screening has improved the detection of ductal dependent CCHDs from 77 to $92 \% .{ }^{11-13}$ Ailes et al estimated that approximately 900 infants with nonsyndromic CCHD were likely to be detected by universal CCHD screening every year in the United States; however, an equal number was likely to be missed. The majority of missed cases of CCHD are lesions that compromise systemic blood flow. ${ }^{11}$ Every year, there are 550 babies born in the United States with PA which translates to approximately 1 in every 7,100 livebirths. ${ }^{14}$ About $60 \%$ of the cases of PA with or without VSD are diagnosed prenatally. ${ }^{15,16}$ The majority of prenatally undiagnosed infants with PA have been diagnosed by universal CCHD 
Asymptomatic term newborn with a heart murmur

Detailed cardiac focused physical exam:

Inspection: dysmorphism, visible apical impulse/hyperdynamic

Palpation: Location of apical impulse, peripheral and central pulses

Auscultation: $1^{\text {st }}$ and $2^{\text {nd }}$ heart sounds- normal or loud, any split. Rhythm Description of the murmur, timing of murmur (systolic, diastolic, continuous). Any radiation. Grading of murmur. Presence of thrill, clicks, extra heart sounds or arrhythmia.

Clinical signs: Respiratory distress, poor perfusion, weak femoral pulses, hepatomegaly, bruit or cyanosis. $\mathrm{SpO}_{2}$ (pre \& post); discrepancy in blood pressures in the four extremities.

Is it a pathological murmur? (any $1 / 4)$ :

1. Systolic murmur $\geq 3 / 6$

2. Diastolic murmur

3. Congestive heart failure

4. Cyanosis- clinical or by pulse-oximetry

\section{Yes}

Serial physical exams $\mathrm{SpO}_{2}$ based $\mathrm{CCHD}$ screening prior to discharge

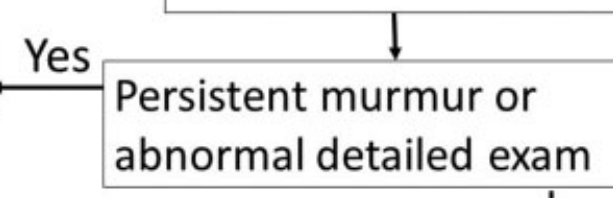

Chest X-ray: increased or decreased pulmonary vascularity cardiomegaly; abnormal shape of cardiac silhouette

EKG: Persistence of upright T wave on V1 beyond 7 days Evidence of chamber enlargement or hypertrophy Evidence of arrhythmia, bundle branch block Pediatric Cardiology consult

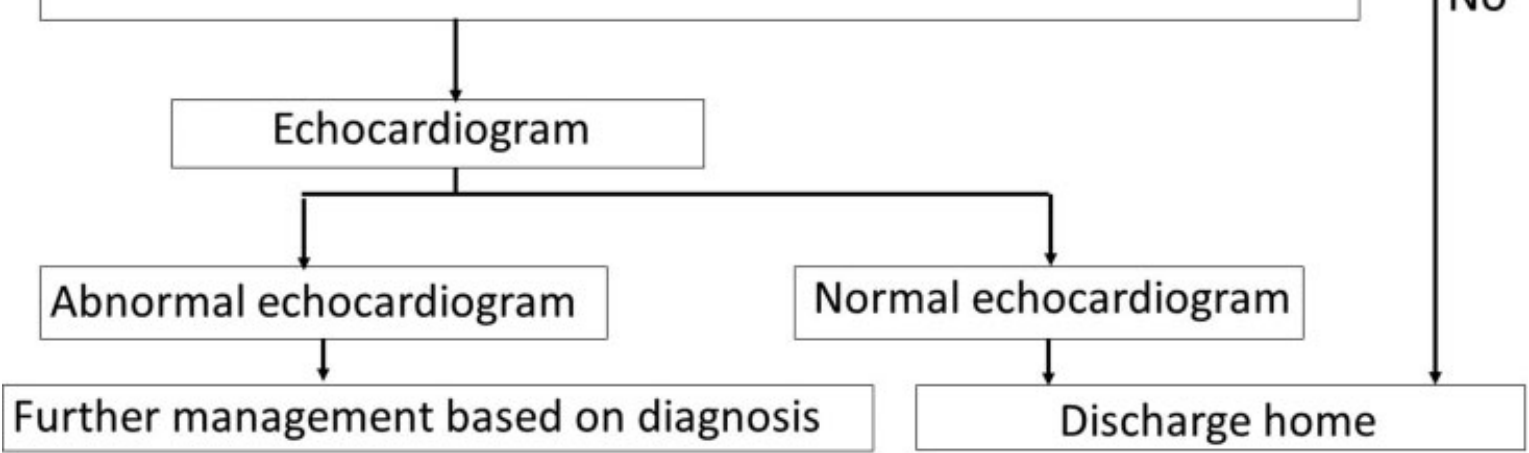

Fig. 5 Approach to an asymptomatic term neonate with a cardiac murmur. An easy to follow algorithm that describes an approach to the management of an asymptomatic term neonate with a cardiac murmur. References: ${ }^{*}$ Nadas, ${ }^{23}{ }^{* *}$ Brockmeier et al, ${ }^{24}$ and Koppel et al. ${ }^{25} \mathrm{CCHD}$, critical congenital heart disease; $\mathrm{SpO}_{2}$, pulse oximetry oxygen saturation. 
screening. $5,11,13,17,18$ In the series reported by de-Wahl Granelli et al and that by Zhao et al, none of the cases of PA ( $n=3$ and 30 , respectively) resulted in false negative oximetry screening. ${ }^{11,13}$ Additionally, two infants with PA reported by Siefkes et al failed oximetry screening, and one of them also had low perfusion index values. ${ }^{19}$ In contrast, Prudhoe et al mentioned one case of PA who was discharged home undiagnosed but no further details regarding clinical course and time of diagnosis were provided. ${ }^{18}$

The reliability of pulse oximetry in detecting CCHD depends on the accuracy of the measurements. Current recommendations are to use pulse oximeters that perform within a close and effective range as the Food and Drug Administration's (FDA) trusted standard. There have been reports of discrepancies between $\mathrm{SpO}_{2}$ and $\mathrm{SaO}_{2}$ in newborn infants, with $\mathrm{SpO}_{2}$ being higher than $\mathrm{SaO}_{2}$ by $3 \%$, while discrepancies up to $10 \%$ have been noted. ${ }^{20,21}$ This discrepancy may have played a role in our patient passing the CCHD screening. However, the infant had $\mathrm{SpO}_{2}$ of $>95 \%$ measured by three different pulse oximeters. Alternatively, a high Qp: Qs ratio would explain the high saturations that we measured in our case.

When oximetry fails, the diagnosis of CCHD depends on detection of abnormal physical findings. It is not uncommon that cardiac murmurs in newborns are often missed or dismissed as benign or innocent. ${ }^{22}$ A murmur is considered pathological (and requires further evaluation with a cardiology consultation, EKG, and echocardiogram) when it is a systolic murmur of grade $\geq 3$ of 6 (loud murmur), any diastolic murmur, presence of either signs of congestive heart failure, or cyanosis (-Fig. 5). ${ }^{23}$ Turbulent flow across the PDA or increased flow across the ventricular outflow tracts may result in a murmur detected on physical examination. Increased Qp causes volume load on the heart, leading to respiratory and hemodynamic stress. The systolic murmur heard in our patient was probably secondary to the PDA (where disappearance of the diastolic component of the continuous murmur may be due to higher pulmonary diastolic pressures and lower systemic pressures) or increased flow across the aortic outflow tract. Vital signs reported in our case suggest that excess volume load can be well tolerated early in life, and not easily detected, at least before an infant is eligible for discharge. After the infant is discharged home, lethargy, cyanosis, or respiratory symptoms may alert the parents and the pediatrician; unfortunately, a few may present with sudden death when the ductus arteriosus closes spontaneously. An upright T-wave on lead V1 in an EKG after 48 hours is highly suggestive of right ventricular strain and would help identify right sided obstructive lesions as shown in our patient.

\section{Conclusions}

Although pulse oximetry screening prior to newborn discharge has enhanced timely detection of CCHDs, we need to recognize its limitations even in defects that are rarely missed by $\mathrm{SpO}_{2}$ screening. This report reinforces the importance of careful serial physical examinations of infants after birth and prior to their discharge. Pulse oximetry screening is meant to augment the detailed examination of newborns, a sizeable number of whom may have a CCHD.

\section{Authors' Contributions}

D.S., F.R.P., H.S., F.F.I., and S.L. made substantial contributions to conception, design, and drafting of the manuscript. All the authors have critically revised and approved the final version of the manuscript. All authors agree to be accountable for all aspects of the work.

\section{Funding}

D.S.'s effort was supported by the Children's Miracle Network research grant at University of California Davis, Child Health Research Grant from University of California Davis Pediatrics and First Tech Federal Credit Union, and Neonatal Resuscitation Program Research Grant from Canadian Pediatric Society.

H.S.'s effort was supported by the National Center for Advancing Translational Sciences (NCATS), National Institutes of Health (NIH; through grant UL1 TR001860 and linked award KL2 TR001859), and by Eunice Kennedy Shriver National Institute of Child Health \& Human Development (NICHD; 1R21 1HD099239-01). The funding agencies had no role in the design of this manuscript. S.L.'s effort was supported by NICHD: 5 R01 HD072929 09.

Conflict of Interest

The authors have no conflict of interest to declare.

\section{Acknowledgments}

We thank the parents of the infant for giving us permission to publish this case.

We would also like to thank Dr. Nanak Boparai, MD, and Ms. Alyssa Benton, RN, for their timely diagnosis in this patient by way of serial and thorough physical examination and attention to detail.

\section{References}

1 Payne RM, Johnson MC, Grant JW, Strauss AW. Toward a molecular understanding of congenital heart disease. Circulation 1995;91 (02):494-504

2 Mahle WT, Newburger JW, Matherne GP, et al; American Heart Association Congenital Heart Defects Committee of the Council on Cardiovascular Disease in the Young, Council on Cardiovascular Nursing, and Interdisciplinary Council on Quality of Care and Outcomes Research American Academy of Pediatrics Section on Cardiology And Cardiac Surgery Committee On Fetus And Newborn. Role of pulse oximetry in examining newborns for congenital heart disease: a scientific statement from the AHA and AAP. Pediatrics 2009;124(02): 823-836

3 Abu-Harb M, Hey E, Wren C. Death in infancy from unrecognised congenital heart disease. Arch Dis Child 1994;71(01):3-7

4 Abu-Harb M, Wyllie J, Hey E, Richmond S, Wren C. Presentation of obstructive left heart malformations in infancy. Arch Dis Child Fetal Neonatal Ed 1994;71(03):F179-F183

5 Ailes EC, Gilboa SM, Honein MA, Oster ME. Estimated number of infants detected and missed by critical congenital heart defect screening. Pediatrics 2015;135(06):1000-1008 
6 Park MK. Pediatric Cardiology for Practitioners 5th ed. St. Louis, MO: Mosby; 2007

7 da Cruz E, Ivy D, Jaggers J, eds. Pediatric and Congenital Cardiology, Cardiac Surgery and Intensive Care. London, United Kingdom: Springer-Verlag; 2014

8 Rudolph A. Congenital Diseases of the Heart: Clinical-Physiological Considerations, 3rd ed. Oxford, United Kingdom: Blackwell Publishing; 2009

9 The Secretary of Health \& Human Services letter. Accessed on February 24, 2021 at: https://www.hrsa.gov/sites/default/files/ hrsa/advisory-committees/heritable-disorders/reports-recommendations/response-congenital-cyanotic.pdf

10 Glidewell JGrosseSD, Riehle-Colarusso T, et al. Actions in support of newborn screening for critical congenital heart disease-United States, 2011-2018. MMWR Morb Mortal Wkly Rep 2019;68 (05):107-111

11 de-Wahl Granelli A, Wennergren M, Sandberg K, et al. Impact of pulse oximetry screening on the detection of duct dependent congenital heart disease: a Swedish prospective screening study in 39,821 newborns. BMJ 2009;338:a3037

12 Koppel RI, Druschel CM, Carter T, et al. Effectiveness of pulse oximetry screening for congenital heart disease in asymptomatic newborns. Pediatrics 2003;111(03):451-455

13 Zhao QM, Ma XJ, Ge XL, et al; Neonatal Congenital Heart Disease screening group. Pulse oximetry with clinical assessment to screen for congenital heart disease in neonates in China: a prospective study. Lancet 2014;384(9945):747-754

14 Mai CT, Isenburg JL, Canfield MA, et al; National Birth Defects Prevention Network. National population-based estimates for major birth defects, 2010-2014. Birth Defects Res 2019;111 (18):1420-1435

15 Tzifa A, Barker C, Tibby SM, Simpson JM. Prenatal diagnosis of pulmonary atresia: impact on clinical presentation and early outcome. Arch Dis Child Fetal Neonatal Ed 2007;92(03):F199-F203
16 Tuo G, Volpe P, Bondanza S, et al. Impact of prenatal diagnosis on outcome of pulmonary atresia and intact ventricular septum. J Matern Fetal Neonatal Med 2012;25(06):669-674

17 Martin GR, Ewer AK, Gaviglio A, et al. Updated strategies for pulse oximetry screening for critical congenital heart disease. Pediatrics 2020;146(01):e20191650

18 Prudhoe S, Abu-Harb M, Richmond S, Wren C. Neonatal screening for critical cardiovascular anomalies using pulse oximetry. Arch Dis Child Fetal Neonatal Ed 2013;98(04):F346-F350

19 Siefkes H, Kair L, Tancredi DJ, et al. Oxygen saturation and perfusion index-based enhanced critical congenital heart disease screening. Am J Perinatol 2020;37(02):158-165

20 Rosychuk RJ, Hudson-Mason A, Eklund D, Lacaze-Masmonteil T. Discrepancies between arterial oxygen saturation and functional oxygen saturation measured with pulse oximetry in very preterm infants. Neonatology 2012;101(01):14-19

21 Afzal B, Chandrasekharan P, Tancredi DJ, Russell J, Steinhorn RH, Lakshminrusimha S. Monitoring gas exchange during hypothermia for hypoxic-ischemic encephalopathy. Pediatr Crit Care Med 2019;20(02):166-171

22 Braudo MRowe RD. Auscultation of the heart early neonatal period. Am J Dis Child 1961;101(05):575-586

23 Nadas AS. Approach to diagnosis of congenital heart disease without recourse to special tests. Circulation 1959;20:602-605

24 Brockmeier K, Nazal R, Sreeram N. The electrocardiogram of the neonate and infant. J Electrocardiol 2016;49(06):814-816

25 Koppel RI, Mahle WT. Novel Methods to Screen for Heart Disease in Infants. Congenital heart defects: from origin to treatment. Oxford University Press; 2010:107-115. Available at: https:// books.google.com/books?hl=en\&lr=\&id=MJg-i_juO0YC\&oi=fnd \& $\mathrm{pg}=\mathrm{PA} 107 \& \mathrm{dq}=$ electrocardiogram + screening + tool + for $+\mathrm{CChD}+\&$ ots=t_Do23DVVI\&sig=URP5A6u0zMJFHY-pOsbjHzS4RYo\#v=onepage $\&$ q $=$ electrocardiogram $\% 20$ screening $\% 20$ tool $\% 20$ for $\% 20 \mathrm{CChD}$ $\& \mathrm{f}=$ false 